\title{
Challenges and benefits of integrating diverse sampling strategies in the observation of cardiovascular risk factors (ORISCAV-LUX 2) study
}

Ala'a Alkerwi ${ }^{1 *}$ D, Jessica Pastore ${ }^{1}$, Nicolas Sauvageot ${ }^{1}$, Gwenaëlle Le Coroller ${ }^{1}$, Valéry Bocquet ${ }^{1}$, Marylène d'Incau ${ }^{1}$, Gloria Aguayo 1, Brice Appenzeller', Dritan Bejko', Torsten Bohn', Laurent Malisoux1', Sophie Couffignal', Stephanie Noppe ${ }^{2}$, Charles Delagardelle ${ }^{2}$, Jean Beissel ${ }^{2}$, Anna Chioti ${ }^{3}$, Saverio Stranges ${ }^{1,4}$ and Jean-Claude Schmit ${ }^{3}$

\begin{abstract}
Background: It is challenging to manage data collection as planned and creation of opportunities to adapt during the course of enrolment may be needed. This paper aims to summarize the different sampling strategies adopted in the second wave of Observation of Cardiovascular Risk Factors (ORISCAV-LUX, 2016-17), with a focus on population coverage and sample representativeness.

Methods: Data from the first nationwide cross-sectional, population-based ORISCAV-LUX survey, 2007-08 and from the newly complementary sample recruited via different pathways, nine years later were analysed. First, we compare the socio-demographic characteristics and health profiles between baseline participants and non-participants to the second wave. Then, we describe the distribution of subjects across different strategy-specific samples and performed a comparison of the overall ORISCAV-LUX2 sample to the national population according to stratification criteria.
\end{abstract}

Results: For the baseline sample (1209 subjects), the participants (660) were younger than the non-participants (549), with a significant difference in average ages ( 44 vs 45.8 years; $P=0.019$ ). There was a significant difference in terms of education level $(P<0.0001), 218$ (33\%) participants having university qualification vs. 95 (18\%) non-participants. The participants seemed having better health perception $(p<0.0001)$; $455(70.3 \%)$ self-reported good or very good health perception compared to 312 (58.2\%) non-participants. The prevalence of obesity $(P<0.0001)$, hypertension $(P<0.0001)$, diabetes $(P=0.007)$, and mean values of related biomarkers were significantly higher among the non-participants. The overall sample (1558 participants) was mainly composed of randomly selected subjects, including 660 from the baseline sample and 455 from other health examination survey sample and 269 from civil registry sample (constituting in total 88.8\%), against only 174 volunteers (11.2\%), with significantly different characteristics and health status. The ORISCAV-LUX2 sample was representative of national population for geographical district, but not for sex and age; the younger (25-34 years) and older (65-79years) being underrepresented, whereas middle-aged adults being overrepresented, with significant sex-specific difference $(p<0.0001)$.

Conclusion: This study represents a careful first-stage analysis of the ORISCAV-LUX2 sample, based on available information on participants and non-participants. The ORISCAV-LUX datasets represents a relevant tool for epidemiological research and a basis for health monitoring and evidence-based prevention of cardiometabolic risk in Luxembourg.

Keywords: Sample representativeness, Population-based study, Follow-up studies, population health, Epidemiology

\footnotetext{
* Correspondence: alaa.alkerwi@lih.lu

'Luxembourg Institute of Health $(\mathrm{LIH})$, Department of Population Health, 1A

rue Thomas Edison, L-1445 Strassen, Luxembourg

Full list of author information is available at the end of the article
}

(c) The Author(s). 2019 Open Access This article is distributed under the terms of the Creative Commons Attribution 4.0 International License (http://creativecommons.org/licenses/by/4.0/), which permits unrestricted use, distribution, and reproduction in any medium, provided you give appropriate credit to the original author(s) and the source, provide a link to the Creative Commons license, and indicate if changes were made. The Creative Commons Public Domain Dedication waiver (http://creativecommons.org/publicdomain/zero/1.0/) applies to the data made available in this article, unless otherwise stated. 


\section{Background}

The optimal allocation of available resources is the concern of every investigator and decision-maker before choosing a population-based study design [1]. Despite the well-known benefits of conducting longitudinal surveys to advance epidemiology and clinical research, full baseline sample participation in follow-up studies is challenging. Over time, initial participants may drop out of the study due to death, move abroad or simply refuse to respond to the successive rounds of surveys, due to loss of interest for added complex examinations and time consuming measurements. This poor compliance and low participation rate may impact dataset quality and sample relevance.

The "Observation of Cardiovascular Risk Factors in Luxembourg" (ORISCAV-LUX) survey, conducted between November 2007 and January 2009, was the first nationwide cross-sectional survey of cardiovascular health monitoring in Luxembourg [2]. It aimed to establish baseline information on the prevalence of "traditional" cardiovascular risk factors, including obesity, hypertension, diabetes mellitus, lipid disorder, smoking and physical inactivity among the general adult population. Complete details about study design, sampling scheme, non-response handling, sample representativeness of the population were published elsewhere [2, 3]. Briefly, a total of 1432 subjects (response rate $32.2 \%$ ) were successfully recruited, slightly beyond the estimated necessary sample size and the expected participation rate. The comparison of participants and non-participants in the ORISCAV-LUX survey revealed that their distribution and profiles were comparable in terms of cardiovascular morbidity indicators, including prescribed medications, hospital admission and medical measures [3].

From a public health and research perspective, the health surveys need to be repeated at regular intervals to monitor the evolution and allow the development of coherent and effective strategies of prevention. In 2016, the second wave ORISCAV-LUX study was initiated to follow-up the same baseline sample of participants. An extended set of health indicators, new clinical examinations and self-reported information were integrated in the second round of data collection.

Indeed, reaching a suitable number of participants, based on the initial baseline ORISCAV-LUX sample, was challenging. A nationally representative sample is a prerequisite to meet public health goals. In this respect, we had to adapt our planning and suggest alternative solutions to our sampling scheme in order to ensure sufficient sample size, and hence the validity of constituted dataset and the resulting statistics. The objective of this paper is to summarize the different sampling strategies adopted in the ORISCAV-LUX2, with a focus on the evaluation of population coverage and the sample representativeness. Operational issues associated with the implementation of this adaptive sampling schemes were described hereafter in the methodology.

\section{Methods \\ Data collection procedures}

Similar to the ORISCAV-LUX baseline study [2], the participation to the second wave included 3 main steps: filling in a self-reported questionnaire; clinical and anthropometric measurements according to standardised operating procedures; and blood, urine and hair samples collection.

The participants in the baseline study received an invitation letter together with an information leaflet, a coupon-answer and a pre-paid envelop, suggesting them to take part in the second wave. The subjects who accepted to participate were asked either to fill in the online questionnaire accessible with a unique identification code, or simply request a paper version indicating their preferred language (French, German, Portuguese or English). The consented subjects were rapidly contacted by phone, to schedule an appointment at one of the nearest study centres.

\section{Added questionnaires}

Several new questionnaires were added, including a self-administered questionnaire filled by the participant at home and another one focusing on the medical aspects completed during the interview by the research nurse. Information on demographic and socio-economic characteristics, personal and family history as well as lifestyle-related questionnaires were collected based on the same tools as the baseline study. New general health status modules were introduced including quality of life 36-Item Short Form Health Survey (SF-36) [4], evaluation of autonomy [Activities of Daily Living (ADL) and Instrumental Activities of Daily Living (IADL) instruments] [5], sleep habits [6], Mini-Mental State Examination test [7], [Centre for Epidemiologic Studies Depression Scale (CES-D)] [8], constipation [9], social support, women's health, cardiovascular history, detailed personal diseases and chronic conditions, medication, vitamins and supplements intake and pollution-related questionnaire (Please see Additional files 1 and 2). An electronic version of a 174-item Food Frequency Questionnaire (e-FFQ) was also used in the second wave.

\section{New anthropometric and clinical examinations}

In addition to weight, height, waist, and hip circumferences, proximal thigh girth and bio-impedancemetry body composition (Tanita ${ }^{\circ}$ BC 418) were measured. Further parameters concerning cardiac function including triple blood pressure and pulse rate measurements in sitting and supine position, ECG, pulse wave velocity (Complior ${ }^{\circledast}$ ); physical function (including finger tapping, 
grip strength, balance, chair rises, walking speed, and step test by using Actiheart ${ }^{\circ}$ were also incorporated. Objective measures of physical activity (7-day accelerometer data by using Actigraph ${ }^{\bullet}$ accelerometer), as well as mental function (five cognitive tests by using the Cambridge Neuropsychological Test Automated Battery $\mathrm{CANTAB}^{\circ}$ ) were also collected.

\section{Sampling schemes \\ Original baseline sample enrolment}

In December 2015, the baseline 1432 participants were re-contacted to take part in the second round, except those who had already refused (15 subjects) to take part in follow-up studies. During the 9 years, the missions of the Inspectorate of Social Security (IGSS) who provided the initial sample based on the National Insurance Registry were reformed. This institution was no longer allowed to share nominative data and therefore unable to update the addresses of the participants. They could however confirmed the crude numbers of subjects who quitted the country to live abroad (51) and deceased (23), without link to the identification code, yielding a total eligible sample of 1343 addresses. To avoid sending useless invitations to inexistent subjects, an active research on national website www.editus.lu, as well as direct phone calls were performed to confirm the accuracy of delivery addresses and to correct potential changes.

Following this procedure, further 134 addresses $(10 \%$ of the eligible sample) could not be found and hence were categorised as "non-recovered". Then, the invitations were sent to the final identified and validated sample of 1209 addresses. Out of these, 353 (29.2\%) refused to take part in the second wave, 158 (13.1\%) never answered after three reminders. Further 13 (1.1\%) were excluded during the recruitment process due to their move abroad, physical disability or language incapacity. After this scheme, a total of 685 subjects accepted to participate. Among them, 25 subjects (3.6\%) did not attend, or cancelled their repeated appointments, and could not be enrolled until the end of the study and hence were categorised as "reluctant/non recruited". Finally, 660 subjects, constituting $54.6 \%$ of the invited sample (Fig. 1).

\section{Alternative strategies}

To overcome the drop of the initial sample size and preserve a nationally representative sample, three alternative sampling strategies were thereafter implemented to recruiting a new complementary sample from:

1) The civil national registry: With the support of the Ministry of Health and in collaboration with the Government IT Centre [Centre des Technologies de l'Information de l'Etat (CTIE)], a new additional random sample of 4737 subjects, accounting for a large anticipated non-participation rate was selected. This number was calculated based on the initial sampling procedure used in the first wave [3]. According to its legal status, the CTIE is the sole institution possessing the nominative information about all resident people in Luxembourg and is apt to approach directly the

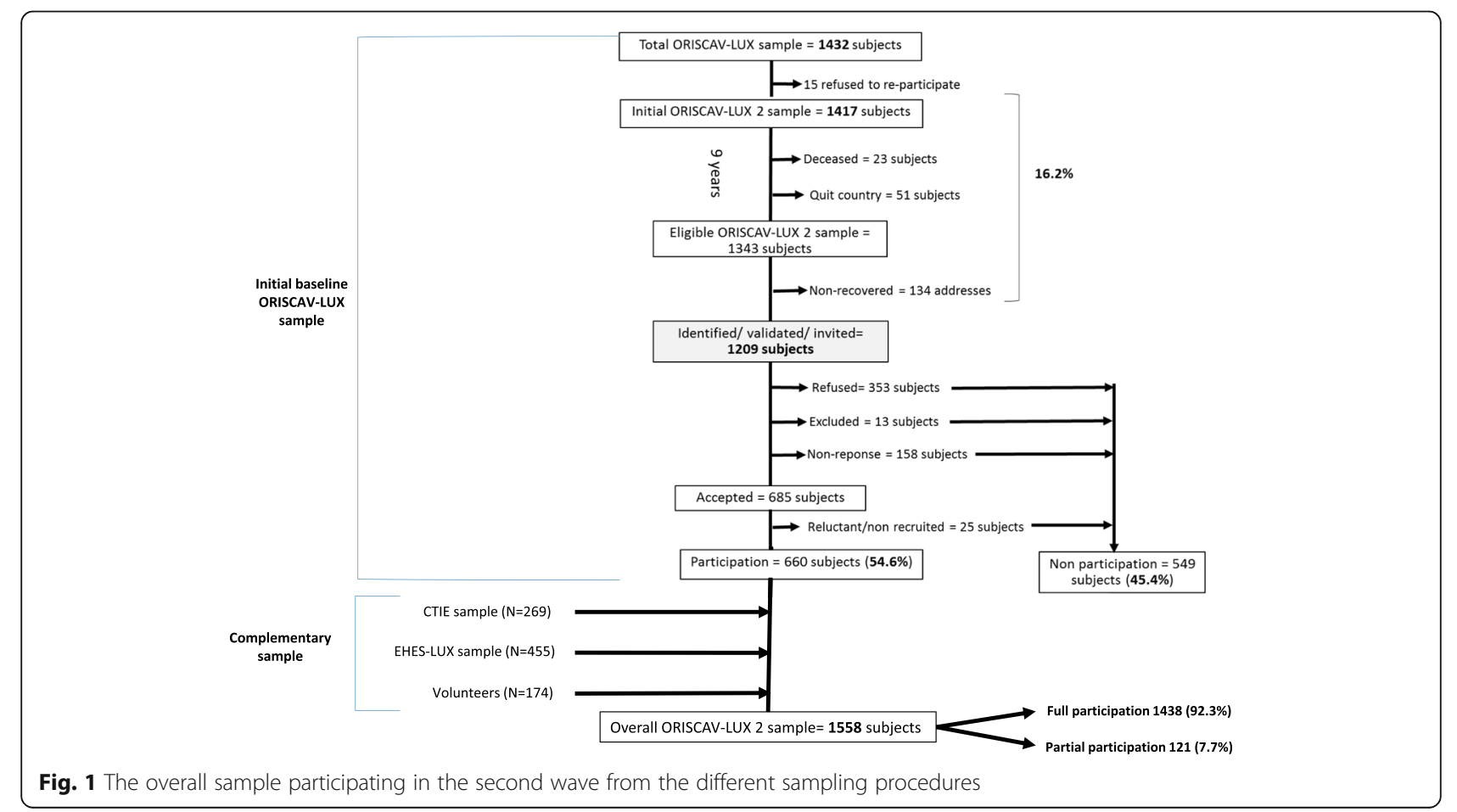


residents via a nominative mailing. In this context, short letters were sent to the selected subjects summarizing briefly the objective of the study and asking them to send their complete address to the recruiting institute [Luxembourg institute of Health (LIH)] in case of consent. Once the invited subjects agreed to send their personal data via the email dedicated to the project or via a phone call, they were registered in our databank. Thereafter, the same enrolment process begun by sending detailed information about the study and the consented subjects were contacted by our administrative assistant to fix an appointment in our premises. For logistic and practical considerations, the CTIE mailing was dispatched in several batches, each sent to almost 500 subjects, over a period of 6 months. Despite the huge efforts to prepare and organise this procedure, it seemed unhelpful; participation rate constituted only 5.7\% (269 participants out of almost 4700 invited subjects).

2) European Health Examination Survey (EHES-LUX) list of participants: Using an existing address list of participants who took part in EHES-LUX study carried out by the LIH. Out of a total of 1431 subjects invited, 455 participants were recruited for the ORISCAV-LUX 2, constituting a participation rate of almost $32 \%$.

3) Volunteers: A call for volunteers was advertised through divers means of communication, for example the LIH social networks (Facebook, Twitter), ORISCAVLUX project's website (www.oriscav.lih.lu), the national press, the media, and during outreach events for the general public. For this purpose, study-oriented poster and leaflet were prepared in order to attract new participants. Through this pathway, further 174 volunteers were enrolled (Fig. 1).

Between January 2016 and January 2018, a total of 1558 subjects were recruited in the second wave of the study, including 1438 participants (92.3\%) with full participation, and 121 (7.7\%) with partial participation. Full participation means that the participants filled in the self-reported questionnaires, attended their appointments and underwent clinical and anthropometric examinations, and provided blood urine and samples. Partial participation entails that the participants answered only self-reported questionnaires, without attending the nurse interview in our study centres.

\section{Statistical methods}

Using the baseline ORISCAV-LUX sample, the sociodemographic characteristics and health profiles between participants and non-participants to the second wave were compared. Then, the distribution of subjects across different strategies of sampling was described. A comparison of the overall ORISCAV-LUX 2 sample to the national population according to stratification criteria (age, sex and geographical district) was performed.
Results were presented as numbers (percentages) for categorical variables and mean \pm standard deviation (SD) for continuous variables, by using chi-squared test and one-way ANOVA, respectively. All statistical analyses were performed with Predictive Analytics Software "PASW for Window" version 21.0 software (formerly SPSS Statistics Inc., Chicago, IL, USA)"; $p<0.05$ was considered statistically significant.

\section{Results}

Based on baseline sample (1209 subjects), Table 1 compares the demographic, socio-economic and cardiometabolic risk profiles of participants and non-participants in ORISCAV-LUX2 study. The participants were significantly younger, with no sex-specific difference. There was a significant difference in terms of education level $(P<0.0001), 218$ participants having university qualification (33\%) vs. 95 non-participants (18\%). The participants seemed having a better health perception $(p<0.0001) ; 455$ $(70.3 \%)$ self-reported good or very good health perception Compared to 312 (58.2\%) non-participants.

With regard to selected health-related variables, in general, participants had better cardiometabolic profile compared to non-participants; in fact, prevalence of obesity $(P<0.0001)$, hypertension $(\mathrm{P}<0.0001)$, diabetes $(P=0.007)$, as well as mean values of related biomarkers were significantly higher among non-participants.

Table 2 demonstrates a comparison of the overall ORISCAV-LUX2 sample (1558 subjects) according to the pathway of enrolment. In general, volunteers had a better health profile than other groups. The proportions of the sample are significantly different in terms of age, sex, and prevalence of main cardiometabolic risk factors. In the overall sample, prevalence estimates of diabetes, hypertension and obesity were 4.2, 30 and $19 \%$, respectively).

To assess the representativeness, the overall ORISCAV-LUX2 sample (1558 participants) was compared to the Luxembourg population (342,235 individuals, National Institute of Statistics, STATEC 2011) according to the stratification criteria: sex, age category and district of residence. Table 3 shows that ORISCAV-LUX 2 sample was representative of the population for district, but not for sex and age groups. This age difference was significant for both men and women (both $\mathrm{P}<0.0001)$. Compared to the Luxembourg population, the younger (25-34 years) and older (65-79 years) age groups were underrepresented, whereas middle-aged adults (45-64) were over-represented in the overall sample.

Table 4 shows the completeness of individual survey elements. Data from the self-administered question naires were fully available, including $65 \%$ completed online, and $35 \%$ completed on paper. The percentage of completeness for health questionnaires, e-FFQ 
Table 1 Comparison of participants versus non-participants based on the baseline ORISCAV-LUX sample (1209 subjects)

\begin{tabular}{|c|c|c|c|}
\hline \multirow[t]{2}{*}{ Subjects' characteristics } & \multirow{2}{*}{$\begin{array}{l}\text { Participants } \\
N=660\end{array}$} & \multirow{2}{*}{$\begin{array}{l}\text { Non-participants } \\
N=549\end{array}$} & \multirow[t]{2}{*}{$p$ value } \\
\hline & & & \\
\hline Age, year & $44.02 \pm 11.9$ & $45.79 \pm 13.9$ & 0.019 \\
\hline Sex, Men \% & $335(50.8 \%)$ & $255(46.4 \%)$ & 0.13 \\
\hline District, \% & & & 0.38 \\
\hline Luxembourg & $465(70.6 \%)$ & $401(73.0 \%)$ & \\
\hline Diekirch & $102(15.5 \%)$ & $86(15.7 \%)$ & \\
\hline Grevenmacher & $92(14.0 \%)$ & $62(11.3 \%)$ & \\
\hline Education level, $\%$ & & & $<0.0001$ \\
\hline No diploma & $110(16.8 \%)$ & $188(34.6 \%)$ & \\
\hline Secondary level & $326(49.8 \%)$ & $261(48.0 \%)$ & \\
\hline University level & $218(33.3 \%)$ & $95(17.5 \%)$ & \\
\hline Marital status, \% & & & 0.08 \\
\hline Married & $490(74.4 \%)$ & $374(68.1 \%)$ & \\
\hline Single & $105(15.9 \%)$ & $107(19.5 \%)$ & \\
\hline Divorced & $52(7.9 \%)$ & $50(9.1 \%)$ & \\
\hline Widowed & $12(1.8 \%)$ & $18(3.3 \%)$ & \\
\hline Country of birth,\% & & & 0.01 \\
\hline Luxembourg & $408(61.9 \%)$ & $350(63.8 \%)$ & \\
\hline Portugal & $64(9.7 \%)$ & $78(14.2 \%)$ & \\
\hline Other European country & $152(23.1 \%)$ & $93(16.9 \%)$ & \\
\hline Non-European country & $35(5.3 \%)$ & $28(5.1 \%)$ & \\
\hline Physical activity, \% & & & 0.3 \\
\hline Inactive & $101(16.0 \%)$ & $101(19.4 \%)$ & \\
\hline Moderately active & $179(28.3 \%)$ & $147(28.2 \%)$ & \\
\hline Active & $352(55.7 \%)$ & $273(52.4 \%)$ & \\
\hline Self-reported health perception, \% & & & $<0.0001$ \\
\hline Very good & $70(10.8 \%)$ & 37 (6.9\%) & \\
\hline Good & $385(59.5 \%)$ & $275(51.3 \%)$ & \\
\hline Average & $169(26.1 \%)$ & $204(38.1 \%)$ & \\
\hline Bad & $19(2.9 \%)$ & $18(3.4 \%)$ & \\
\hline Very bad & $4(0.6 \%)$ & $2(0.4 \%)$ & \\
\hline \multicolumn{4}{|l|}{ Cardiometabolic risk profile } \\
\hline Smokers, $\%$ & $113(17.1 \%)$ & $120(21.9 \%)$ & 0.04 \\
\hline Diabetes, \% & $19(2.9 \%)$ & $33(6.2 \%)$ & 0.007 \\
\hline Serum glucose, mg/ml & $93.4 \pm 14.3$ & $96.6 \pm 20.5$ & 0.01 \\
\hline Hypertension, $\%$ & $234(35.5 \%)$ & $255(46.5 \%)$ & $<0.0001$ \\
\hline \multicolumn{4}{|l|}{ Blood pressure, mmHg } \\
\hline SBP & $128.4 \pm 16.0$ & $132.3 \pm 18.8$ & 0.001 \\
\hline DBP & $82.2 \pm 10.8$ & $83.4 \pm 11.2$ & 0.04 \\
\hline $\mathrm{BMl}, \mathrm{kg} / \mathrm{m} 2$ & $25.9 \pm 4.6$ & $27.4 \pm 5.2$ & $<0.0001$ \\
\hline Obesity, \% & $122(18.5 \%)$ & $155(28.3 \%)$ & $<0.0001$ \\
\hline Serum cholesterol, mg/dl & $122.5 \pm 32.4$ & $128.3 \pm 36.9$ & 0.02 \\
\hline Dyslipidaemia, \% & $464(70.8 \%)$ & $415(76.9 \%)$ & 0.02 \\
\hline
\end{tabular}


Table 1 Comparison of participants versus non-participants based on the baseline ORISCAV-LUX sample (1209 subjects) (Continued)

\begin{tabular}{llll}
\hline Subjects' characteristics & Participants & Non-participants & $N=549$ \\
\hline Medication intake, \% & $N=660$ & & \\
Anti-diabetic & $12(1.8 \%)$ & $22(4.0 \%)$ & 0.02 \\
Anti-hypertensive & $78(11.8 \%)$ & $94(17.1 \%)$ & 0.009 \\
Energy intake, Kcal/day & $2409.1 \pm 919.4$ & $2442.1 \pm 958.1$ & 0.58 \\
\hline
\end{tabular}

Results are presented $\mathrm{n}(\%)$ for qualitative variables and mean \pm SD for quantitative variables

$p$ Value from $X^{2}$ test and One way ANOVA for qualitative and quantitative outcomes respectively

BMI: Body Mass Index

questionnaires and clinical and anthropometric measurements varied between 90 to $92 \%$. Physical function measurements (Actigraph $^{\odot}$ and Actiheart $^{\circ}$ ) were lowest (76 and 65\%, respectively). The samples of biological material; blood, urine and hair were all available for 89 , 85 and $55 \%$ of the participants, respectively.

\section{Discussion}

Principal investigators of population surveys face big challenges to manage the data collection as planned and need to create opportunities to adapt the design during the course of data collection in order to ensure quality and external validity of constituted datasets and hence the resulting statistics.

The present manuscript highlights the implementation of adaptive sampling schemes based on our experience in setting up the second wave of the ORISCAV-LUX survey. Indeed, enrolment of the same participants nine years later seemed a highly intricate task. Extensive efforts were required to search and locate former participants in baseline study. A total of 1209 addresses were identified and invited, including 660 subjects (55\%) were successfully enrolled. However, it was crucial to recruit additional subjects and implement further alternative strategies to increase the sample size and enhance national representativeness, including random sampling and call for volunteers.

Consistent to most literature supporting the notion of "healthy participant bias" [10-13], our findings reported that baseline participants in the ORISCAV-LUX2 study were generally healthier and at less risk than those who refused to take part. However, examples of non-significant differences $[14,15]$ or opposite findings have also been reported $[16,17]$. Likewise, the respondents to our invitations were of higher education level than the non-respondents $[12,18,19]$. Such difference and low response rate may imply greater potential for bias survey estimates [20, 21]. In addition, this study confirmed differences in the socio-economic characteristics and cardiometabolic health profile of subjects enrolled via the different pathways, although the major proportion of the overall ORISCAV-LIX2 sample were randomly selected (baseline, EHES-LUX and CITE).
Using an additional list of subjects' addresses was also used in a similar German population-based study [22], with relevant conclusions. Convenience sampling is affordable, and the subjects are readily available. As confirmed by our study, people who volunteer tend to be more health conscious than others [23]. Therefore, samples based only on volunteers are not likely to be representative of the general population, threatening hence the generalisability of the study results. This small volunteers' segment could be excluded from future analyses according to specific research objectives and if deemed necessary after secondary analyses.

With these corrective measures, we raised the number of participants up to 1558, including 1438 subjects (92.3\%) with full participation (filled in questionnaire and attended appointment with the research nurse). Indeed, this is an utmost advantage for the credibility of future analyses on the ORISCAV-LUX2 dataset, targeting prevalence estimates, for example, cognitive performance, arterial stiffness and physical disability.

In observational epidemiology, in particular for studies with a follow-up design, it is important to distinguish scientific inference from population inference [24]. Goldstein et al. [24] suggested to make a clear distinction between descriptive statistics that require representative samples and analytical statistics that attempt to address scientific hypotheses. They argued that selecting a sample that does not represent a real population but has a high degree of heterogeneity in terms of outcome, may provide much more power to investigate the hypotheses of interest. Therefore, they concluded that heterogeneity is desirable to enhance the effectiveness of analysis, and this often implies using sample that is not necessarily representative of the real population [24]. In addition, most of the etiological research on chronic disease (including cardiovascular diseases) issued from highly selected populations with limited representativeness, for example the Framingham study [25] and the Whitehall studies in the UK [26].

Compared to the Luxembourg population, the ORISCAV-LUX2 sample was representative for district of residence, but not for sex and age, with the younger (25-34 years) and older (65-79 years) age groups being underrepresented, whereas middle-aged adults (45-64 
Table 2 Comparison of the participant's characteristics according to the strategy of enrolment, $\mathrm{N}=1558$ subjects

\begin{tabular}{|c|c|c|c|c|c|c|}
\hline Variables & $\begin{array}{l}\text { Baseline ORISCAV-LUX } \\
\text { sample } \\
N=660\end{array}$ & $\begin{array}{l}\text { EHES-LUX } \\
\text { sample } \\
N=455\end{array}$ & $\begin{array}{l}\text { Civil registry sample } \\
\text { (CTIE) } \\
N=269\end{array}$ & $\begin{array}{l}\text { Volunteers } \\
N=174\end{array}$ & $\begin{array}{l}\text { Overall ORISCAV-LUX2 } \\
\text { sample } \\
N=1558\end{array}$ & $p$ value \\
\hline Age, year & $52.7 \pm 12.0$ & $49.1 \pm 10.6$ & $50.7 \pm 12.7$ & $48.7 \pm 14.0$ & $50.9 \pm 12.1$ & $<0.0001$ \\
\hline Sex, Men \% & 335 (50.8\%) & $191(42.0 \%)$ & $125(46.5 \%)$ & 81 (46.5\%) & $732(47.0 \%)$ & 0.04 \\
\hline \multicolumn{7}{|l|}{ District, \% } \\
\hline Diekirch & $102(15.5 \%)$ & 75 (16.5\%) & $46(17.1 \%)$ & $24(13.8 \%)$ & 247 (15.9\%) & 0.39 \\
\hline Grevenmacher & 92 (13.9\%) & $57(12.5 \%)$ & 37 (13.7\%) & $14(8.1 \%)$ & $200(12.8 \%)$ & \\
\hline Luxembourg & 466 (70.6\%) & $323(71.0 \%)$ & $186(69.1 \%)$ & $136(78.2 \%)$ & 1111 (71.3\%) & \\
\hline Education level,\% & & & & & & $<0.0001$ \\
\hline No diploma & 115 (17.5\%) & 60 (13.3\%) & $34(12.6 \%)$ & 17 (9.8\%) & $226(14.6 \%)$ & \\
\hline Secondary level & $302(46.0 \%)$ & $183(40.4 \%)$ & $110(40.9 \%)$ & 45 (25.9\%) & $640(41.2 \%)$ & \\
\hline University level & $239(36.4 \%)$ & $210(64.4 \%)$ & $125(46.5 \%)$ & $112(64.4 \%)$ & $686(44.2 \%)$ & \\
\hline Marital status, \% & & & & & & 0.07 \\
\hline Married & $508(85.1 \%)$ & $326(81.5 \%)$ & $192(80.3 \%)$ & $129(79.6 \%)$ & 1155 (82.6\%) & \\
\hline Single & 67 (11.2\%) & $61(15.3 \%)$ & $31(13.0 \%)$ & 29 (17.9\%) & $188(13.5 \%)$ & \\
\hline Divorced & $8(1.3 \%)$ & $6(1.5 \%)$ & $3(1.3 \%)$ & $1(0.6 \%)$ & $18(1.3 \%)$ & \\
\hline Widowed & $14(2.4 \%)$ & $7(1.8 \%)$ & $13(5.4 \%)$ & $3(1.9 \%)$ & 37 (2.7\%) & \\
\hline Country of birth,\% & & & & & & $<0.0001$ \\
\hline Luxembourg & 408 (61.8\%) & $272(29.7 \%)$ & $150(16.4 \%)$ & 86 (49.4\%) & $916(58.8 \%)$ & \\
\hline Portugal & $64(9.7 \%)$ & $36(7.9 \%)$ & $13(4.83 \%)$ & $8(4.6 \%)$ & $121(7.8 \%)$ & \\
\hline Other European country & $151(22.9 \%)$ & $115(25.3 \%)$ & $80(29.74 \%)$ & $70(40.2 \%)$ & $416(26.7 \%)$ & \\
\hline Non-European country & $37(5.6 \%)$ & $32(7.0 \%)$ & $26(9.7 \%)$ & $10(5.8 \%)$ & $105(6.7 \%)$ & \\
\hline Physical activity, \% & & & & & & $<0.0001$ \\
\hline Inactive & 352 (53.9\%) & $127(28.4 \%)$ & $58(21.6 \%)$ & 35 (20.2\%) & $572(37.1 \%)$ & \\
\hline Moderately active & $111(17 \%)$ & $104(23.3 \%)$ & $86(32.1 \%)$ & $60(34.7 \%)$ & $361(23.4 \%)$ & \\
\hline Active & 190 (29.1\%) & $216(48.3 \%)$ & $124(46.3 \%)$ & $78(45.1 \%)$ & $608(39.5 \%)$ & \\
\hline Self-reported health perception, \% & & & & & & 0.01 \\
\hline Very good & $26(4.0 \%)$ & $20(4.4 \%)$ & $16(6.0 \%)$ & $10(5.8 \%)$ & $72(4.6 \%)$ & \\
\hline Good & $156(23.7 \%)$ & $144(31.9 \%)$ & $85(31.6 \%)$ & $56(32.4 \%)$ & $441(28.4 \%)$ & \\
\hline Average & $376(57.2 \%)$ & $241(53.3 \%)$ & $141(52.4 \%)$ & $87(50.3 \%)$ & $845(54.5 \%)$ & \\
\hline Bad & 91 (13.9\%) & $37(8.2 \%)$ & $21(7.8 \%)$ & $18(10.4 \%)$ & $167(10.8 \%)$ & \\
\hline Very bad & $8(1.2 \%)$ & $10(2.2 \%)$ & $6(2.2 \%)$ & $2(1.2 \%)$ & $26(1.7 \%)$ & \\
\hline \multicolumn{7}{|l|}{ Cardiometabolic Risk profile profile } \\
\hline Smokers, \% & $86(13.1 \%)$ & $60(13.5 \%)$ & $36(13.4 \%)$ & $26(15.3 \%)$ & $208(13.5 \%)$ & 0.93 \\
\hline Diabetes, \% & $37(6.3 \%)$ & $9(2.4 \%)$ & $9(3.7 \%)$ & $2(1.2 \%)$ & $57(4.2 \%)$ & 0.005 \\
\hline Hypertension, \% & $225(36.1 \%)$ & 87 (22.7\%) & 80 (30.9\%) & $36(21.6 \%)$ & $428(29.9 \%)$ & $<0.0001$ \\
\hline Obesity, \% & $136(22.4 \%)$ & $72(19.1 \%)$ & $46(18.1 \%)$ & $15(9.2 \%)$ & $269(19.2 \%)$ & 0.002 \\
\hline $\mathrm{BMI}, \mathrm{kg} / \mathrm{m}^{2}$ & $26.9 \pm 6.7$ & $26.1 \pm 4.9$ & $26.1 \pm 4.6$ & $24.9 \pm 4.3$ & $26.3 \pm 5.7$ & $<0.0001$ \\
\hline \multicolumn{7}{|l|}{ Blood pressure, mmHg } \\
\hline SBP & $130.1 \pm 16.7$ & $125.5 \pm 16.6$ & $126.3 \pm 16.7$ & $123.1 \pm 16.9$ & $127.4 \pm 16.9$ & $<0.0001$ \\
\hline DBP & $80.2 \pm 9.1$ & $77.4 \pm 9.4$ & $78.3 \pm 9.5$ & $75.5 \pm 9.2$ & $78.5 \pm 9.4$ & $<0.0001$ \\
\hline Serum glucose, mg/ml & $96.0 \pm 20.2$ & $91.2 \pm 13.4$ & $92.4 \pm 12.4$ & $89.7 \pm 23.0$ & $93.3 \pm 17.9$ & $<0.0001$ \\
\hline Serum cholesterol, mg/dl & $204.6 \pm 37.7$ & $206.6 \pm 39.1$ & $203.5 \pm 37.8$ & $203.7 \pm 35.9$ & $204.8 \pm 37.9$ & 0.87 \\
\hline
\end{tabular}

Results are presented $\mathrm{n}(\%)$ for qualitative variables and mean \pm SD for quantitative variables

$\mathrm{p}$ Value from $X^{2}$ test and test for qualitative and quantitative outcomes respectively

CTIE Centre des Technologies de I'Information de l'Etat, BMI Body Mass Index 
Table 3 Comparison of ORISCAV-LUX2 participants to the Luxembourg population by sex, age category and district of residence

\begin{tabular}{llll}
\hline Stratification criteria & $\begin{array}{l}\text { Luxembourg population } \\
(N=342,235)\end{array}$ & $\begin{array}{l}\text { Participants }{ }^{\mathrm{a}} \\
(\mathrm{N}=1556)\end{array}$ & $\mathrm{p}$ value \\
& $\mathrm{n}(\%)$ & $(\%)$ & \\
\hline Sex & & & 0.02 \\
Men & $171,158(50.0 \%)$ & $730(46.9 \%)$ & \\
Women & $171,077(50.0 \%)$ & $826(53.1 \%)$ & \\
Age category (years) & & & \\
Women & & & $<0.0001$ \\
25-34 years & $36,895(21.6 \%)$ & $96(11.6 \%)$ & \\
35-44 years & $40,575(23.7 \%)$ & $185(22.4 \%)$ & \\
45-54 years & $37,906(22.2 \%)$ & $235(28.4 \%)$ & \\
55-64 years & $27,725(16.2 \%)$ & $202(24.5 \%)$ & \\
65-79years & $27,976(16.3 \%)$ & $108(13.1 \%)$ & \\
Men & & & $<0.0001$ \\
25-34 years & $36,625(21.4 \%)$ & $89(12.2 \%)$ & \\
35-44 years & $41,519(24.3 \%)$ & $175(24.0 \%)$ & \\
45-54 years & $40,216(23.5 \%)$ & $196(26.8 \%)$ & \\
55-64 years & $28,760(16.8 \%)$ & $176(24.1 \%)$ & \\
65-79years & $24,038(14.0 \%)$ & $94(12.9 \%)$ & \\
District & & & \\
Luxembourg & $251,601(73.5 \%)$ & $1111(71.4 \%)$ & \\
Diekirch & $50,207(14.7 \%)$ & $246(15.8 \%)$ & \\
Grevenmacher & $40,427(11.8 \%)$ & $199(12.8 \%)$ & \\
\hline
\end{tabular}

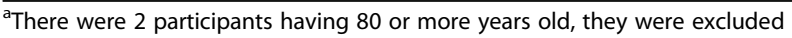

years) were over-represented. In the ORISCAV-LUX2 study, high coverage and sample representativeness is the primary purpose for adopting this hybrid sampling frame as an alternative solution to only use the baseline sample. Interestingly, this initial analyses of the total sample demonstrated that the prevalence of diabetes, hypertension and obesity are comparable to that reported in 2007-2008 (4.2, 30 and 19\%, respectively) [2]. Assuming a steady pattern, this would indicate that integrating diverse sampling strategies in the second wave would not have biased our approach to assess the trend of these disease conditions nine years later. Nevertheless, a number of measures will be considered in future analyses in order to ensure population inference [24]. These include post-survey adjustment of data using weighting techniques to correct for non-response bias [27], as well as using statistical models based on the characteristics of the initial respondents to 'adjust' subsequent analyses [24, 28].

It is worth noting that strict control measures were applied to ensure quality throughout the conduct of the study. Intensive efforts were provided to optimally prepare the fieldwork including nurses training to standard
Table 4 Completeness of individual survey elements

\begin{tabular}{ll}
\hline Survey elements & Completeness n (\%) \\
\hline Self-administered questionnaire & $1557(99.9 \%)^{\mathrm{a}}$ \\
Online & $1008(64.7 \%)$ \\
By paper & $549(35.3 \%)$ \\
Interview with research nurse & \\
Health questionnaire (global) & $1438(92.3 \%)$ \\
e-FFQ & $1432(91.9 \%)$ \\
ADL/IADL & $1437(92.2 \%)$ \\
Anthropometry & $1434(92.0 \%)$ \\
Blood pressure & $1435(92.1 \%)$ \\
CANTAB ${ }^{\oplus}$ & $1419(91.1 \%)$ \\
MMSE-2 & $1436(92.2 \%)$ \\
Tanita ${ }^{\oplus}$ & $1402(90.0 \%)$ \\
ECG & $1428(91.7 \%)$ \\
Complior & $1404(90.1 \%)$ \\
Physical tests (finger tapping test, balance test, & $1431(91.8 \%)$ \\
grip strength test, chair rising test) & \\
Step test / Actiheart & \\
Accelerometry /Actigraph & \\
Blood samples & $1006(64.6 \%)$ \\
Urine samples & $1190(76.4 \%)$ \\
Hair samples & $1382(89.0 \%)$ \\
ane participant attended the interview but refused to fill-in the \\
self-reported questionnaire
\end{tabular}

operating procedures. Several features in the survey process would affect response rate and the type of participation (full vs. partial), such as the way and number of contacts, type of information given to the participants, language of the communication documents, length of interview and feedback received on examination results. While the mean time needed to perform the first wave appointments was less than $2 \mathrm{~h}$, the time for the second wave appointment varied from minimum 01:55 to a maximum of 06:15 (with a mean duration of $03 \mathrm{~h}: 17$ min). Based on the 1438 participants who were interviewed, the completeness of individual survey elements can be described as optimal.

\section{Conclusion}

This study represents a careful first-stage analysis of the ORISCAV-LUX2 sample, based on available information on participants and non-participants. It stresses that special adaptive procedures in sampling design are needed to gain an optimal sample size. These procedures may provide the only practical way to obtain a sample large enough for both scientific research objectives and population inference. A central issue for success of observational studies is to achieve an appropriate balance between adapting the initial sampling procedure during 
data collection and a later adjustment with sample weighting. The available ORISCAV-LUX datasets provide a relevant basis for policy-makers regarding public health monitoring and evidence-based prevention, as well as constitute a valuable tool for epidemiological research on cardiometabolic risk.

\section{Additional files}

Additional file 1: Questionnaires ORISCAV-LUX 2. (Nurse Questionnaire) English version. (PDF $872 \mathrm{~kb}$ )

Additional file 2: Questionnaires ORISCAV-LUX 2. (Home-based Questionnaire) English version. (PDF 898 kb)

\section{Abbreviations}

ADL: Activities of Daily Living; ANOVA: Analysis of variance; BMl: Body Mass Index; CANTAB: Cambridge Neuropsychological Test Automated Battery; CESD: Centre for Epidemiologic Studies Depression Scale; CITE: Centre des Technologies de I'Information de l'Etat; e-FFQ : Electronic Food Frequency Questionnaire; EHES-LUX : European Health Examination Survey in Luxembourg; IADL: Instrumental Activities of Daily Living; IGSS: General Inspectorate of Social Security; LIH: Luxembourg institute of Health; MMSE2: Mini-Mental State Examination test-version 2; ORISCAV-LUX: Observation of Cardiovascular risk factors study in Luxembourg (Baseline); ORISCAVLUX2: Second wave of the Observation of Cardiovascular risk factors study in Luxembourg; PASW : Predictive Analytics Software; SD: Standard deviation; SF-36: Quality of life 36-Item Short Form Health Survey; STATEC: Institut national de la statistique et des études économiques du Grand-Duché de Luxembourg

\section{Acknowledgments}

The authors thank first the participants in ORISCAV-LUX2 study. Our thanks extend to Pierrette Weisgerber, Robert Wagener and Nico Majerus for collaboration to CTIE sample selection and expedition of invitations. Sincere acknowledgements to the following persons involved in different stages of ORISCAV-LUX data collection: Myriam Alexandre, Charlotte Lieunard, Graziella Ambroset, Agnès Columeau, Laura Da Silva, Anne-Marie Hanff, Alain Noirhomme, Diana Pauseiro, Lynn Nothar, Jessica Calmes, Aurélie Wiederkehr, Daniela Valoura Esteves, Jérôme Graas, Manon Gantenbein, Cathy Fousse, Maxime Larcelet, Hanène Samouda, Yvan Devaux, Laetitia Huiart and all trainees and summer students. The help of Maria Ruiz and Jessica Barré to facilitate access to the list of participants in the EHES-LUX study is appreciated. We are grateful to the University of Liège, School of Public Health, for allowing us to use their Food Frequency Questionnaire.

\section{Funding}

Ministry of Research (an in-house funding). No role to be declared of the funding body in the design of the study and collection, analysis, and interpretation of data and in writing the manuscript.

\section{Availability of data and materials}

Data sharing is not applicable to this article as no datasets were generated or analyzed during the current study.

\section{Authors' contributions}

AA is the principal investigator of ORISCAV-LUX $1 \& 2$ survey, she contributed to statistical analysis, perform results interpretation and drafted the manuscript. JP is the data manager of ORISCAV-LUX 2 dataset, provided information on flow chart and participants' recruitment. NS, GLC, VB performed the statistical analysis and contributed to results interpretation. MDI coordinated the fieldwork for data collection. JCS involved in the instigation of the ORISCAV-LUX2 study, coordinated between the authorities (Ministry of Health and CTIE) to get access to additional population sample. GA, BA, DB, TB, LM (alphabetic order) are co-investigators and involved in the ORISCAV-LUX2 study design and tools selection. SC, AC, SN, CD, JB, SS, JCS contributed to the critical revision of the manuscript and intellectual content. All authors read and approved the final version.

\section{Ethics approval and consent to participate}

All participants were duly informed and consented in writing to take part in the study. The study design and information collected were approved by the National Research Ethics Committee ( ${ }^{\circ}$ 201,505/12) and the National Commission for Private Data Protection.

\section{Consent for publication}

Not applicable.

\section{Competing interests}

The authors declare that they have no competing interests.

\section{Publisher's Note}

Springer Nature remains neutral with regard to jurisdictional claims in published maps and institutional affiliations.

\section{Author details}

${ }^{1}$ Luxembourg Institute of Health (LIH), Department of Population Health, 1A rue Thomas Edison, L-1445 Strassen, Luxembourg. ${ }^{2}$ Centre Hospitalier du Luxembourg $(\mathrm{CHL})$, Luxembourg City, Luxembourg. ${ }^{3}$ Ministry of Health, Directorate of Health, Luxembourg City, Luxembourg. ${ }^{4}$ Department of Epidemiology \& Biostatistics, Schulich School of Medicine \& Dentistry, Western University, London, ON N6A 5C1, Canada.

Received: 18 June 2018 Accepted: 28 January 2019

Published online: 04 February 2019

\section{References}

1. Reilly M. Optimal sampling strategies for two-stage studies. Am J Epidemiol. 1996;143(1):92-100.

2. Alkerwi A, Sauvageot N, Donneau AF, Lair ML, Couffignal S, Beissel J, et al. First nationwide survey on cardiovascular risk factors in grand-duchy of Luxembourg (ORISCAV-LUX). BMC Public Health. 2010;10:468.

3. Alkerwi A, Sauvageot N, Couffignal S, Albert A, Lair ML, Guillaume M. Comparison of participants and non-participants to the ORISCAV-LUX population-based study on cardiovascular risk factors in Luxembourg. BMC Med Res Methodol. 2010;10:80.

4. Ware JE Jr, Sherbourne CD. The MOS 36-item short-form health survey (SF-36). I. Conceptual framework and item selection. Med Care. 1992;30(6):473-83.

5. Svestkova O. International classification of functioning, disability and health of World Health Organization (ICF). Prague Med Rep. 2008;109(4):268-74.

6. Buysse DJ, Reynolds CF 3rd, Monk TH, Berman SR, Kupfer DJ. The Pittsburgh sleep quality index: a new instrument for psychiatric practice and research. Psychiatry Res. 1989;28(2):193-213.

7. Folstein MF, Robins LN, Helzer JE. The mini-mental state examination. Arch Gen Psychiatry. 1983;40(7):812.

8. Radloff LS. The CES-D scale: a self report depression scale for research in the general population. Appl Psychol Meas. 1977;1:385-401.

9. Agachan F, Chen T, Pfeifer J, Reissman P. Wexner SD. A constipation scoring system to simplify evaluation and management of constipated patients. Dis Colon Rectum. 1996;39(6):681-5.

10. Klesges RC, Williamson JE, Somes GW, Talcott GW, Lando HA, Haddock CK. A population comparison of participants and nonparticipants in a health survey. Am J Public Health. 1999;89(8):1228-31.

11. Hoeymans N, Feskens EJ, Van Den Bos GA, Kromhout D. Non-response bias in a study of cardiovascular diseases, functional status and self-rated health among elderly men. Age Ageing. 1998;27(1):35-40.

12. Pullen E, Nutbeam D, Moore L. Demographic characteristics and health behaviours of consenters to medical examination. Results from the welsh heart health survey. J Epidemiol Community Health. 1992;46(4):455-9.

13. Goldberg M, Chastang JF, Leclerc A, Zins M, Bonenfant S, Bugel I, et al. Socioeconomic, demographic, occupational, and health factors associated with participation in a long-term epidemiologic survey: a prospective study of the French GAZEL cohort and its target population. Am J Epidemiol. 2001;154(4):373-84.

14. Manjer J, Carlsson S, Elmstahl S, Gullberg B, Janzon L, Lindstrom M, et al. The Malmo diet and Cancer study: representativity, cancer incidence and mortality in participants and non-participants. Eur J Cancer Prev. 2001;10(6):489-99.

15. Weinehall L, Hallgren CG, Westman G, Janlert U, Wall S. Reduction of selection bias in primary prevention of cardiovascular disease through involvement of primary health care. Scand J Prim Health Care. 1998;16(3):171-6. 
16. Tennant A, Badley EM. Investigating non-response bias in a survey of disablement in the community: implications for survey methodology. J Epidemiol Community Health. 1991;45(3):247-50.

17. Locker D. Effects of non-response on estimates derived from an oral health survey of older adults. Community Dent Oral Epidemiol. 1993;21(2):108-13.

18. Pietila AM, Rantakallio P, Laara E. Background factors predicting nonresponse in a health survey of northern Finnish young men. Scand J Soc Med. 1995;23(2):129-36.

19. van't Hof MA, Burema J. Assessment of bias in the SENECA study. Eur J Clin Nutr. 1996;50 Suppl 2:S4-8.

20. Hansen $M H$, Hurwitz WN. The problem of non-response in sample surveys. J Am Stat Assoc. 1946;41(236):517-29.

21. Hill A, Roberts J, Ewings $P$, Gunnell D. Non-response bias in a lifestyle survey. J Public Health Med. 1997;19(2):203-7.

22. Scheidt-Nave C, Kamtsiuris P, Gosswald A, Holling H, Lange M, Busch MA, et al. German health interview and examination survey for adults (DEGS) design, objectives and implementation of the first data collection wave. BMC Public Health. 2012;12:730.

23. Annula Review of nursing Research. In: Fitzpatrick JJ, editor. Alcohol use, Misuse, Abuse, and Dependance. New York: Springer Publishing Company, Inc; 2005.

24. Goldstein H, Lynn, Peter, Muniz-Terrera, Graciela, Hardy, Rebecca, O'Muircheartaigh, Colm, Skinner, Chris J. And Lehtonen, Risto. Population sampling in longitudinal suverys. Longitudinal and Life Course Studies 2015; 6 (4):pp. 447-475.

25. Mahmood SS, Levy D, Vasan RS, Wang TJ. The Framingham heart study and the epidemiology of cardiovascular disease: a historical perspective. Lancet. 2014;383(9921):999-1008.

26. Marmot M, Brunner E. Cohort profile: the Whitehall II study. Int J Epidemiol. 2005;34(2):251-6.

27. Locker D. Response and nonresponse bias in oral health surveys. J Public Health Dent. 2000;60(2):72-81.

28. Etter JF, Perneger TV. Analysis of non-response bias in a mailed health survey. J Clin Epidemiol. 1997;50(10):1123-8.

Ready to submit your research? Choose BMC and benefit from:

- fast, convenient online submission

- thorough peer review by experienced researchers in your field

- rapid publication on acceptance

- support for research data, including large and complex data types

- gold Open Access which fosters wider collaboration and increased citations

- maximum visibility for your research: over $100 \mathrm{M}$ website views per year

At $\mathrm{BMC}$, research is always in progress.

Learn more biomedcentral.com/submissions 